\title{
Promoting physical activity in patients with rheumatoid arthritis: rheumatologists' and health professionals' practice and educational needs
}

\author{
Emalie J. Hurkmans • V. de Gucht • S. Maes • \\ Andreas J. Peeters $\cdot$ H. Karel Ronday • \\ Thea P. M. Vliet Vlieland
}

Received: 25 January 2011 /Revised: 24 June 2011 /Accepted: 31 August 2011 / Published online: 13 September 2011

(C) The Author(s) 2011. This article is published with open access at Springerlink.com

\begin{abstract}
Despite the proven health benefits, patients with rheumatoid arthritis (RA) are found to be less physically active than their healthy peers. The aim of this study was to examine to what extent and how physical activity, defined as any bodily movement resulting in energy expenditure, is currently promoted by health care providers in patients with RA and how they perceive their competencies and educational needs. For this cross-sectional study, Dutch rheumatologists, rheumatology clinical nurse specialists, and expert physical therapists were sent a postal survey including four domains: attitudes towards physical activity in RA, advices given to patients with RA, and perceived competencies and educational needs. A total of 126 rheumatologists (50\%), 132 clinical nurse specialists $(56 \%)$, and 112 physical therapists $(53 \%)$ returned the questionnaire. More than $90 \%$ agreed that physical activity
\end{abstract}

E. J. Hurkmans $(\bowtie) \cdot$ T. P. M. Vliet Vlieland

Department of Rheumatology, Leiden University Medical Center, C1-R, P.O. Box 9600, Leiden, The Netherlands

e-mail: e.j.hurkmans@lumc.nl

V. de Gucht $\cdot$ S. Maes

Health Psychology, Leiden University,

Leiden, The Netherlands

\section{A. J. Peeters}

Department of Rheumatology, Reinier de Graaf Gasthuis,

Delft, The Netherlands

H. K. Ronday

Department of Rheumatology, Haga Hospital,

The Hague, The Netherlands

T. P. M. Vliet Vlieland

Department of Orthopaedics, Leiden University Medical Center, Leiden, The Netherlands is an important health goal for RA patients and regularly advised their patients to engage in physical activity. Public health recommendations for moderate-intensity physical activity were found attainable in RA patients by $66 \%$, $74 \%$, and $65 \%$ and were by used by $19 \%, 41 \%$, and $49 \%$ of them, respectively. On average, respondents rated their competency to promote physical activity as low to medium, and $54 \%, 85 \%$, and $72 \%$ of the respondents expressed a need for additional education regarding this topic. Rheumatologists, nurses, and physical therapists considered regular physical activity to be an important health goal for RA patients. The majority of them commonly gave advice on physical activity but felt not sufficiently competent and indicated a need for additional education.

Keywords Health professionals · Health promotion · Physical activity $\cdot$ Rheumatoid arthritis $\cdot$ Rheumatologists

\section{Introduction}

Regular physical activity, defined as any bodily movement resulting in energy expenditure, is associated with a reduction of morbidity and mortality in the general population $[1,2]$. In patients with rheumatoid arthritis (RA), physical activity has also various disease-specific benefits such as improved functional ability [3] and reduction of pain [4]. A considerable number of RA patients, however, do not experience these health benefits. It has been found that the total amount of time spent on physical activity is lower in RA patients and they spent less time on moderate-intensity activities compared to the general population [5].

Given these observations, health care providers are more and more encouraged to promote physical activity in RA 
patients [2, 5-7]. Regarding the effectiveness of efforts to promote physical activity in RA, a number of randomized controlled trials have been published $[8,9]$. These studies have shown positive results with regard to physical activity behavior $[8,9]$, including a significant increase in the proportion of patients meeting public health recommendations for physical activity (physical activity at a moderateintensity level for at least $30 \mathrm{~min}$ on at least 5 days of the week and/or physical activity at a vigorous-intensity level for at least $20 \mathrm{~min}$ on at least 3 days of the week $[8,10]$ ), perceived health status [9], and muscle strength [9]. With respect to the practice of promotion of physical activity by health care providers, little data are currently available. Fontaine et al. [11] found that $42 \%$ of the patients with arthritis reported ever being advised by a health professional to increase their physical activity. In this study, results for patients with RA were not presented separately from those with other rheumatic conditions. Munneke et al. [12] demonstrated in a cross-sectional study that rheumatologists and physical therapists had in general a positive attitude towards physical exercise for RA patients but that they were less positive concerning physical exercise at a high-intensity level. Another study by Iversen et al. [13], among 25 rheumatologists and 140 patients with RA, concluded that their attitudes and beliefs varied considerably and were less positive than anticipated, in particular with respect to aerobic exercise. Furthermore, only $17 \%$ of the rheumatologists felt competent to effectively instruct their patients with regard to physical activity. This study also showed that rheumatologists' beliefs in the effectiveness of physical exercise for RA patients as well as their advice to patients were associated with their own physical activity levels [13].

Given the scarcity of knowledge on the promotion of physical activity in RA patients, the aim of the present study was to determine the attitudes of rheumatologists, clinical nurse specialists, and physical therapists towards physical activity and the extent to which they promote physical activity in RA patients by making use of public health recommendations, their perceived health promotion competencies, and related educational needs. Moreover, the relationship between age, sex, and level of physical activity of health care providers on the one side and their attitudes, practices, and perceived competencies on the other side was studied.

\section{Methods}

Subjects and study design

For this cross-sectional study, Dutch registered rheumatologists and rheumatologists in training $(n=253)$, clinical nurse specialists working in rheumatology $(n=236)$, and physical therapists with a special expertise in rheumatic conditions $(n=211)$ (further designated as expert physical therapists in this paper) were invited to participate. The Dutch Association for Rheumatology and the Dutch Association of Health Professionals in Rheumatology supported this study and provided the addresses of rheumatologists and clinical nurse specialists. Expert physical therapists were selected by means of the registries of regional arthritis networks of physical therapists $(n=$ 211). In April 2008, all potential participants were sent a questionnaire with a pre-stamped envelope. A reminder was sent after 3 to 6 weeks.

The study was judged to be no medical research in the sense of the Medical Research Involving Human Subjects Act (in Dutch: WMO) by the Medical Ethics Review Committee of the LUMC so that no individual informed consent was obtained (health care providers were free to either fill in the questionnaire or not).

The questionnaire

Rheumatologists', clinical nurse specialists', and physical therapists' attitudes, practices, perceived competencies, and educational needs with regard to the promotion of physical activity were examined by means of a self-developed questionnaire consisting of 23 questions. Topics in the subscale attitudes were scored with respect to agreement (five-point scale) and items in the subscale advice with respect to frequency (four-point scale). The subscale competencies related to the extent a statement was applicable and used ten-point Likert scales. The questionnaire was first pilot-tested among ten rheumatologists, clinical nurse specialists, and physical therapists and subsequently adapted to improve its readability and specificity.

\section{Attitudes towards physical activity in RA patients}

The attitudes subscale comprised five statements, and respondents were asked to rate each statement on a fivepoint scale (totally agree, agree, neither disagree nor agree, disagree, and totally disagree). An example statement was: "Moderate-intensity physical activity according to the public health recommendation (physical activity at a moderateintensity level for $30 \mathrm{~min}$ on at least 5 days per week) is attainable for patients with RA who have a high level of disease activity" (see Table 2) (Cronbach's alpha 0.94).

\section{Advices given to $R A$ patients}

The advices subscale consisted of four statements that were rated on a four-point scale (always, regularly, sometimes, 
and never). For example, "I advise patients with RA to do regular physical activity" (see Table 3) (Cronbach's alpha 0.94) (see Table 3).

\section{Perceived competencies regarding the promotion of physical activity in $R A$ patients}

This domain comprised 13 statements that were rated on a ten-point scale $(0=\mathrm{I}$ do not have this competence; $10=\mathrm{I}$ have this competence). For example "Teach patients to break their important health goals down into more concrete, achievable goals" (see Table 4) (Cronbach's alpha 0.96). All scores were added-up and divided by 13 , resulting in a total score.

\section{Educational needs}

One question asked every respondent whether he or she would be interested to follow an educational course on the promotion of physical activity among patients with RA. Participants were offered a yes/no answer category.

\section{Physical activity}

The Short Questionnaire to Assess Health-Enhancing Physical Activity (SQUASH) was used to assess physical activity in the participating health care providers [14]. The SQUASH contains questions regarding physical activity related to commuting activities, leisure time and sports activities, household activities, and activity at work and school. For each of these domains, an activity level is determined, making use of three queries: activity days per week, average activity time per day, and intensity of the activity (light, moderate, vigorous). For each of these domains, the activity level is measured using two queries: days per week and average time per day. The time per day (in minutes) was multiplied by the days per week to calculate the total minutes the health professional spent on this specific activity. The scores of all domains were than added up, resulting in the final score. The SQUASH was shown to be a moderately reliable and valid questionnaire [14]. The SQUASH can be used to assess whether someone meets the public health recommendation for physical activity or not.

\section{Statistical analysis}

Categorical data were described as numbers and percentages. In case of Gaussian distribution, continuous data were described as means and standard deviations (SD). Differences between the three groups of professionals were analyzed by means of ANOVA, Student's $t$-test, or chi-square test.

To facilitate comparisons between the different groups of health care providers, in the attitudes subscale the scores for totally agree and agree and totally disagree and disagree and in the advices subscale the scores for always and regular and sometimes and never were merged.

Spearman rank correlations were computed to explore univariate associations between health care providers' age (years) and current level of physical activity (minutes) on the one side and the attitudes (item scores), frequency of advice (item scores), and competencies (total score) on the other side. To study the impact of sex, the scores of the attitudes (item scores), frequency of advice (item scores), and competencies (total score) were compared between men and women with Mann-Whitney $U$ test.

All analyses were conducted using SPSS 16.0 (SPSS Chicago, IL, USA).

\section{Results}

\section{Sociodemographics}

A total of 126 rheumatologists (including rheumatologists in training) (50\%), 132 clinical nurse specialists (56\%), and 112 physical therapists $(53 \%)$ returned the questionnaire on time (Table 1). The average ages of the rheumatologists, clinical nurse specialists, and physical therapists were 48 , 45, and 45 years, respectively.

Rheumatologists worked significantly more hours per week (mean, $41 \mathrm{~h}$ ) than physical therapists (mean, $34 \mathrm{~h}$ ) or

Table 1 Characteristics of rheumatologists, clinical nurse specialists, and physical therapists participating in a cross-sectional study on the promotion of physical activity in patients with RA

\begin{tabular}{lccc}
\hline & Rheumatologists & $\begin{array}{l}\text { Clinical nurse } \\
\text { specialists }\end{array}$ & $\begin{array}{l}\text { Physical } \\
\text { therapists }\end{array}$ \\
\hline Age & $48(9)$ & $45(9)$ & $45(10)$ \\
Female, $n(\%)$ & $59(49 \%)$ & $125(95 \%)$ & $63(56 \%)$ \\
Work situation, $n(\%)$ & & & \\
Hospital & $118(94 \%)$ & $109(83 \%)$ & $24(21 \%)$ \\
Private practice & $0(0 \%)$ & $0(0 \%)$ & $73(65 \%)$ \\
Other & $9(7 \%)$ & $37(28 \%)$ & $16(14 \%)$ \\
Hours practicing & $41(9)$ & $26(7)$ & $34(11)$ \\
Years of experience & $12(9)$ & $7(6)$ & $21(10)$ \\
Amount of patients & $92(67)$ & $33(25)$ & $6(7)$ \\
$\quad$ with RA treated & & & \\
per month & & $2,710(982)$ & $3,023(1034)$ \\
SQUASH, $n$ (min) & $2,538(946)$ & $80 \%$ & $80 \%$ \\
$\begin{array}{l}\text { Meet the public } \\
\text { recommendation, } \\
n(\%)\end{array}$ & $55 \%$ & & \\
\hline
\end{tabular}

Values are expressed as mean (SD) unless indicated otherwise \#SQUASH Short Questionnaire to Assess Health-Enhancing Physical Activity 
clinical nurse specialists (mean, $26 \mathrm{~h}$ ) (all $p<0.001$ ). Physical therapists had significantly more job seniority (mean, 21 years) than rheumatologists (12 years) or clinical nurse specialists ( 7 years) (all $p<0.001)$. Most rheumatologists and clinical nurse specialists worked in hospitals $(n=118(94 \%)$ and $n=109$ (83\%), respectively), while most physical therapists worked in private practice $(n=73,65 \%)$. Rheumatologists treated significantly more patients with RA per month (mean $n=92)$ than clinical nurse specialists $(n=33)$ or physical therapists $(n=6)($ all $p<0.001)$.

According to the SQUASH, rheumatologists spent on average the least time on physical activity $(2,538$; SD 946 min per week) compared to clinical nurse specialists $(2,710$; SD 982 min per week) $(p=0.15)$ and physical therapists $(3,023$; SD 1,034 min per week) $(p<0.001)$. The proportion of rheumatologists that reported to meet the public health recommendation for moderate-intensity physical activity [1] was 55\%, which was significantly lower compared to clinical nurse specialists $(80 \%)$ and physical therapists $(80 \%)$ (both $p<0.001$ ).

\section{Attitudes towards physical activity in RA patients}

Table 2 shows that the majority of rheumatologists $(n=118$, $94 \%)$, clinical nurse specialists $(n=132,100 \%)$, and physical therapists $(n=109,100 \%)$ agreed that obtaining and/or maintaining a sufficient level of physical activity is an important health goal in the management of patients with RA.

Most rheumatologists $(n=82,66 \%)$, clinical nurse specialists $(n=98,74 \%)$, and physical therapists $(n=71,65 \%)$ agreed that the public health recommendation for physical activity is attainable for RA patients; and 105 rheumatologists (84\%), 113 clinical nurse specialists (86\%), and 87 physical therapists $(80 \%)$ agreed that it is also safe for patients with RA.

A small minority of rheumatologists $(n=20,16 \%)$, clinical nurse specialists $(n=22,17 \%)$, and physical therapists $(n=18$, $17 \%$ ) agreed that the public health recommendation for physical activity is attainable for patients with RA who have a high level of disease activity. In addition, a minority of rheumatologists $(n=45,36 \%)$, clinical nurse specialists $(n=$ $49,37 \%)$, and physical therapists $(n=31,28 \%)$ agreed that trying to meet this level of physical activity is safe for patients with RA who have a high level of disease activity.

No statistically significant differences were found between the proportions of rheumatologists, clinical nurse specialists, and expert physical therapists scoring agree or totally on any of the items in this subscale.

Advices given to RA patients

Table 3 shows that advice on physical activity was always or on a regular basis given by the majority of the rheumatologists

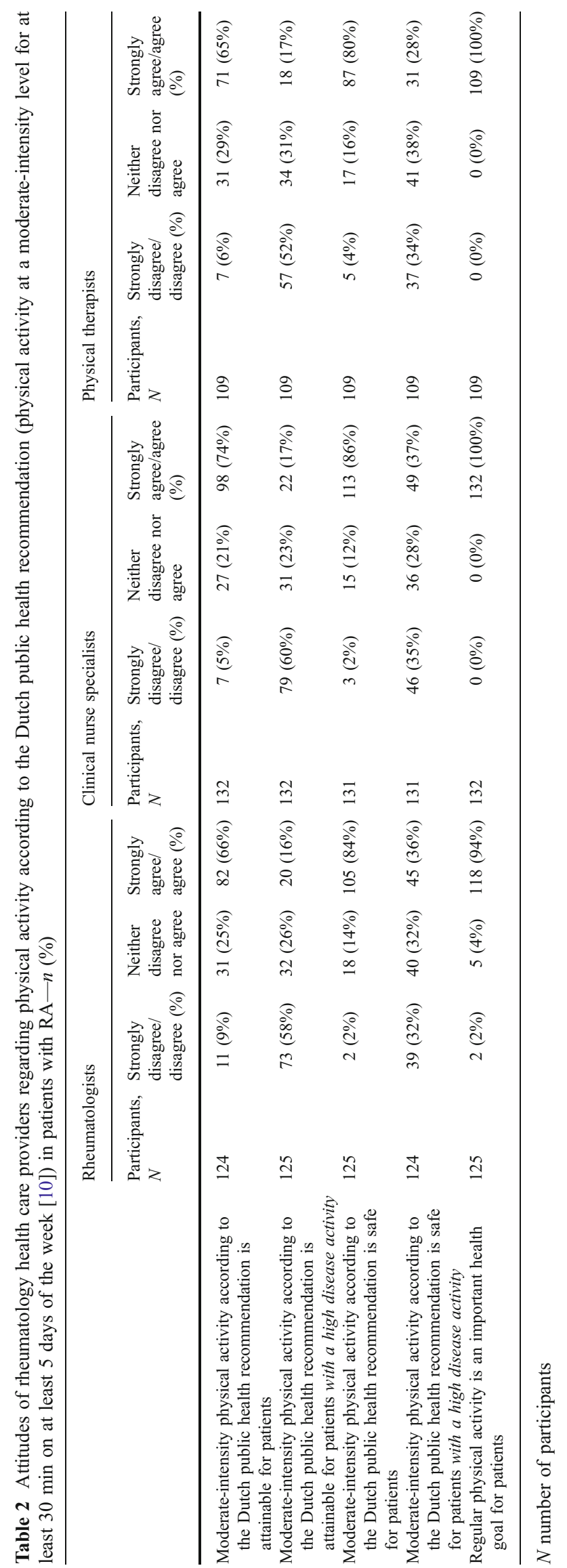


Table 3 Advices of rheumatology health care providers with regard to physical activity in patients with RA- $n$ (\%)

\begin{tabular}{|c|c|c|c|c|c|c|c|c|c|}
\hline & \multicolumn{3}{|c|}{ Rheumatologists } & \multicolumn{3}{|c|}{ Clinical nurse specialists } & \multicolumn{3}{|c|}{ Physical therapists } \\
\hline & $N$ & $\begin{array}{l}\text { Always/ } \\
\text { regularly }\end{array}$ & $\begin{array}{l}\text { Sometimes/ } \\
\text { never }\end{array}$ & $N$ & $\begin{array}{l}\text { Always/ } \\
\text { regularly }\end{array}$ & $\begin{array}{l}\text { Sometimes/ } \\
\text { never }\end{array}$ & $N$ & $\begin{array}{l}\text { Always/ } \\
\text { regularly }\end{array}$ & $\begin{array}{l}\text { Sometimes/ } \\
\text { never }\end{array}$ \\
\hline $\begin{array}{l}\text { I advise patients to take care of regular } \\
\text { physical activity }\end{array}$ & 124 & $107(86 \%)$ & $17(14 \%)$ & 129 & $122(95 \%)$ & $7(5 \%)$ & 110 & $109(99 \%)$ & $1(1 \%)$ \\
\hline $\begin{array}{l}\text { I advise patients with recent onset RA to take } \\
\text { care of regular physical activity }\end{array}$ & 124 & $109(88 \%)$ & $15(12 \%)$ & 128 & $119(93 \%)$ & $9(7 \%)$ & 109 & $109(100 \%)$ & $0(0 \%)$ \\
\hline $\begin{array}{l}\text { I advise patients with established RA to take } \\
\text { care of regular physical activity }\end{array}$ & 124 & $103(83 \%)$ & $21(17 \%)$ & 129 & $120(93 \%)$ & $9(7 \%)$ & 110 & $107(97 \%)$ & $3(3 \%)$ \\
\hline $\begin{array}{l}\text { When I advise patient about physical activity, } \\
\text { I use the Dutch public health recommendation } \\
\text { as basis }\end{array}$ & 124 & $23(19 \%)$ & $101(81 \%)$ & 128 & $52(41 \%)$ & $76(59 \%)$ & 110 & $54(49 \%)$ & $56(51 \%)$ \\
\hline
\end{tabular}

$N$ number of participants who provided a response

( $n=107,86 \%)$, clinical nurse specialists $(122,95 \%)$, and physical therapists $(n=109,99 \%)$. Most of the health professionals commonly advise both patients with recent onset and established RA to engage in physical activity.

Few rheumatologists $(n=23,19 \%)$, but more clinical nurse specialists $(n=52,41 \%)$ and physical therapists $(n=$ $54,49 \%$ ), use the public health recommendation on moderate-intensity physical activity [10] for their advice to RA patients. These differences were statistically significant (both $p<0.001$ ).
Perceived competencies to promote physical activity in RA patients

The mean perceived competencies score to promote physical activity was 5.6 (1.4) for rheumatologists, 6.6 (1.2) for clinical nurse specialists, and $6.8(1.0)$ for physical therapists (for all scores, see Table 4). The differences between the rheumatologists and clinical nurse specialists and between rheumatologists and physical therapists were statistically significant (both $p<0.001$ ).

Table 4 Perceived competencies of rheumatology health care providers to promote physical activity in RA patients [expressed as mean (standard deviation)]

Rheumatologists Clinical nurse Physical therapists specialists

Get patients to see important health recommendations as their own personal goal

Get patients to believe in or trust their own abilities to achieve important health goals

Regularly provide patients with understandable information about their progress toward important health goals

Get patients to seek help from significant others (e.g., partner, children, friends) when striving toward important health goals

Get patients to compare their (lack of) progress toward important health goals with that of other patients who have made sufficient progress

Help patients plan steps or activities that are necessary to achieve important health goals

Teach patients how they can monitor their progress toward important health goals

Prevent patients from over-criticizing themselves when they encounter difficulties in the pursuit of important health goals

Get patients to reward themselves for each small step on the way toward achieving important health goals

Prevent patients from letting other important goals, events, or people distract them from pursuing their important health goals

Prevent patients from giving up on their important health goals if they have experienced problems or setbacks

Teach patients to control negative emotions and stress that could prevent them from reaching important health goals

Teach patients to break their important health goals down into more concrete, achievable goals

Total score

\begin{tabular}{lll}
$6.2(1.6)$ & $6.8(1.3)$ & $7.0(1.1)$ \\
$6.4(1.5)$ & $6.9(1.3)$ & $7.3(0.9)$ \\
$6.3(1.8)$ & $6.9(1.5)$ & $7.4(1.0)$ \\
$6.2(1.7)$ & $6.9(1.2)$ & $6.7(1.4)$ \\
$5.0(2.0)$ & $5.7(1.6)$ & $5.9(1.7)$ \\
$5.3(1.8)$ & $6.9(1.5)$ & $7.2(1.1)$ \\
$5.3(1.7)$ & $6.4(1.5)$ & $6.9(1.2)$ \\
$5.6(1.9)$ & $6.8(1.3)$ & $6.9(1.1)$ \\
$5.3(1.9)$ & $6.8(1.3)$ & $6.8(1.2)$ \\
$5.1(1.8)$ & $6.2(1.3)$ & $6.3(1.4)$ \\
$5.4(1.8)$ & $6.5(1.3)$ & $6.6(1.3)$ \\
$4.9(1.8)$ & $6.3(1.4)$ & $6.4(1.4)$ \\
$5.6(1.8)$ & $6.8(1.4)$ & $7.1(1.1)$ \\
$5.6(1.4)$ & $6.6(1.2)$ & $6.8(1.0)$ \\
\hline
\end{tabular}




\section{Educational needs}

The proportions of rheumatologists that indicated that they were interested in additional education on the promotion of physical activity was significantly lower $(n=68,54 \%)$ compared to clinical nurse specialists $(n=112,85 \%)$ and physical therapists $(n=81,72 \%)$ (both $p<0.001)$.

Association between health care providers' characteristics and their attitudes, advices, and perceived competencies regarding physical activity

Apart from a significant correlation between the physical therapists' level of physical activity and the frequency of physical activity advice to RA patients $(r=0.323, p=0.001)$, no associations between health care providers' characteristics (age and sex) or physical activity level (according to the SQUASH) on the one hand and any items on the attitudes subscales, advices subscales, or the perceived competencies (total score) on the other hand were found (results not shown).

\section{Discussion}

This study among rheumatology health care providers found that about two thirds of the rheumatologists, clinical nurse specialists, and expert physical therapists consider physical activity to be an important health goal for RA patients and the public health recommendations for moderate-intensity physical activity attainable for patients with stable disease. Most of them commonly advise their patients with RA to engage in physical activity, with a minority referring to public health recommendations to define the desired intensity and frequency. More than half of all participants expressed the need for additional education regarding the promotion of physical activity.

In our study, rheumatologists, clinical nurse specialists, and physical therapists had a relatively positive attitude towards physical activity in patients with RA. This result is in line with the conclusion of a previous Dutch study [12] but is slightly in contrast with the findings of Iversen et al. [13] who observed a more negative attitude among rheumatologists. Comparisons among studies are however difficult to make as different methods were used. Iversen et al. studied rheumatologists' attitudes towards exercise by making a subdivision into range of motion exercises, strengthening exercises, and aerobic capacity exercises. Rheumatologists found aerobic capacity exercises to be the least useful for the management of RA [13]. In our study, we used the public health recommendation for moderateintensity physical activity [10] as a reference for the intensity and frequency of physical activity among RA patients. Over the last years, this public health recommendation for physical activity was promoted among health professionals in rheumatology by means of recommendations [6,7] and was communicated to the general population by means of various mass media.

Although rheumatologists, clinical nurse specialists, and physical therapists had in general a positive attitude towards physical activity in patients with RA, the large majority considered the public health recommendations for physical exercise as not attainable and unsafe in patients with high levels of disease activity. In the last years, however, a number of studies have demonstrated that even in RA patients with a high disease activity even vigorous physical activity is both effective and safe $[3,4]$. This discrepancy between theory and practice indicates that rheumatologists' and health professionals' knowledge with regard to the effectiveness and safety of physical activity for RA patients should perhaps be further enhanced.

This study also showed that the large majority of rheumatologists, clinical nurse specialists, and physical therapists were reported to regularly provide patients with RA with advice on physical activity. In the study by Fontaine et al. [11], it was found that only $42 \%$ of patients with arthritis reported to have ever received advice on physical activity. Although that study included patients with other forms of arthritis than RA, the observed discrepancy may indicate that health care providers in our study have overestimated the regularity of their advice and/or that the message has not been well understood or received by patients participating in the study by Fontaine et al., substantiating the need for improvement of health care providers' communication skills [11]. In the study by Iversen et al. [13], only $17 \%$ of the rheumatologists felt competent to effectively instruct their patients with regard to physical activity. The present study showed that Dutch rheumatologists also rate their competence in this area as low. These low ratings may reflect that rheumatologists consider the promotion of physical activity to a large extent the responsibility of a physical therapist or a clinical nurse specialist rather than of their own. Nevertheless, still more than half of the rheumatologists stated that they were willing to participate in additional education to improve their health promotion skills with regard to physical activity, although a significantly larger proportion of the nurses and physical therapists was prepared to do so.

Iversen et al. [13] found that rheumatologists who were physically active had a more positive attitude towards physical activity and were more likely to advise their patients to do physical activity. Although we used a different methodology, our study revealed no such associations between the physical activity level of the 
health care provider and their attitudes and advices among rheumatologists and clinical nurse specialists. However, physical therapists that were more physically active appeared to advise physical activity more frequently. A possible explanation is the difference in methodology, and therefore direct comparisons of our results with theirs are difficult.

Our study has a few limitations. First, it has a crosssectional design so that no conclusions on causal relationships can be drawn. Furthermore, the questionnaire was based on self-report and could therefore have elicited socially desired answers. We tried to reduce social desirability by ensuring that the data collection was anonymous, but self-reports are never free of this bias. Ideally, observing and analyzing actual consultations, as was done by Iversen et al. [13], are preferable for further research. Furthermore, the average number of RA patients treated by physical therapists was relatively low $(n=6$ per month), which could have biased their perspective with regard to the extent that they promote physical activity in this patient group. Another limitation of this study is the use of a self-developed questionnaire which has not been validated in different populations of health professionals. Despite a good internal consistency and its ability to detect differences among groups of health professionals in the present study, its clinimetric properties need to be further examined.

In addition, while a response rate of $50 \%$ for health care providers is certainly acceptable, this could also have biased our results [15]. Despite these limitations, this study included a representative sample of rheumatologists, clinical nurse specialists, and physical therapists working with patients with RA.

In conclusion, the large majority of rheumatologists and healthy professionals believe that patients with RA can meet the public health recommendations for physical activity, with the exception of patients with an active disease. Public health recommendations are, however, not frequently used to set physical activity goals for RA patients at this moment. More than half of the health care providers expressed a need for further education on the promotion of physical activity. Further research should focus on the best way to train health professionals in the promotion of physical activity in patients with RA.

\section{Disclosures None.}

Open Access This article is distributed under the terms of the Creative Commons Attribution Noncommercial License which permits any noncommercial use, distribution, and reproduction in any medium, provided the original author(s) and source are credited.

\section{References}

1. Haskell WL, Lee IM, Pate RR, Powell KE, Blair SN, Franklin BA, Macera CA, Heath GW, Thompson PD, Bauman A (2007) Physical activity and public health: updated recommendation for adults from the American College of Sports Medicine and the American Heart Association. Med Sci Sports Exerc 39:1423-1434

2. Macera CA, Hootman JM, Sniezek JE (2003) Major public health benefits of physical activity. Arthritis Rheum 49:122-128

3. de Jong Z, Munneke M, Zwinderman AH, Kroon HM, Jansen A, Ronday KH et al (2003) Is a long-term high-intensity exercise program effective and safe in patients with rheumatoid arthritis? Results of a randomized controlled trial. Arthritis Rheum 48:2415-2424

4. Van Den Ende CH, Vliet Vlieland TP, Munneke M, Hazes JM (2000) Dynamic exercise therapy for rheumatoid arthritis. Cochrane Database Syst Rev 2:CD000322

5. van den Berg MH, de Boer IG, le Cessie S, Breedveld FC, Vliet Vlieland TP (2007) Are patients with rheumatoid arthritis less physically active than the general population? Clin Rheumatol 13:181-186

6. (2003) Work group recommendations: 2002 Exercise and Physical Activity Conference, St. Louis, Missouri. Session VI: population approaches to health promotion and disability prevention through physical activity. Arthritis Rheum 49:477

7. (2003) Work group recommendations: 2002 Exercise and Physical Activity Conference, St. Louis, Missouri. Session V: evidence of benefit of exercise and physical activity in arthritis. Arthritis Rheum 49:453-454

8. van den Berg MH, Ronday HK, Peeters AJ, le Cessie S, van der Giesen FJ, Breedveld FC, Vliet Vlieland TP (2006) Using Internet technology to deliver a home-based physical activity intervention for patients with rheumatoid arthritis: a randomized controlled trial. Arthritis Rheum 55:935-945

9. Brodin N, Eurenius E, Jensen I, Nisell R, Opava CH, PARA Study Group (2008) Coaching patients with early rheumatoid arthritis to healthy physical activity: a multicenter, randomized, controlled study. Arthritis Rheum 59:325-331

10. Nelson ME, Rejeski WJ, Blair SN, Duncan PW, Judge JO, King AC, Macera CA, Castaneda-Sceppa C (2007) Physical activity and public health in older adults: recommendation from the American College of Sports Medicine and the American Heart Association. Med Sci Sports Exerc 39:1435-1445

11. Fontaine KR, Bartlett SJ, Heo M (2005) Are health care professionals advising adults with arthritis to become more physically active? Arthritis Rheum 53:279-283

12. Munneke M, de Jong Z, Zwinderman AH, Ronday HK, van den Ende CH, Vliet Vlieland TP, Hazes JM (2004) High intensity exercise or conventional exercise for patients with rheumatoid arthritis? Outcome expectations of patients, rheumatologists, and physiotherapists. Ann Rheum Dis 63:804-808

13. Iversen MD, Fossel AH, Daltroy LH (1999) Rheumatologistpatient communication about exercise and physical therapy in the management of rheumatoid arthritis. Arthritis Care Res 12:180 192

14. Wendel-Vos GC, Schuit AJ, Saris WH, Kromhout D (2003) Reproducibility and relative validity of the short questionnaire to assess health-enhancing physical activity. J Clin Epidemiol $56: 1163-1169$

15. Response rates - an overview. American Association for Public Opinion Research (AAPOR). 29 Sept 2008 